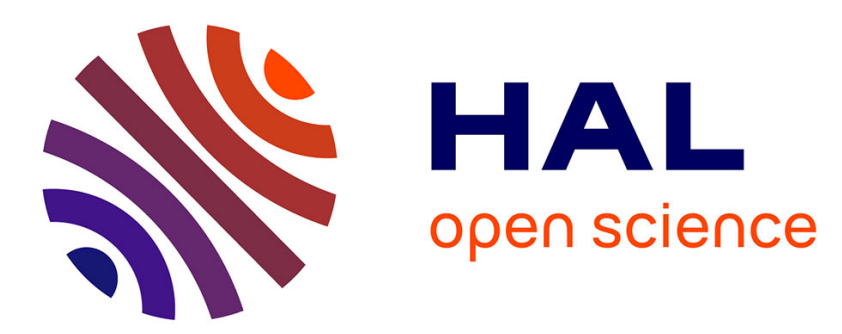

\title{
Are geochemical regime shifts identifiable in river waters? Exploring the compositional dynamics of the Tiber River (Italy)
}

Caterina Gozzi, Vasilis Dakos, Antonella Buccianti, Orlando Vaselli

\section{- To cite this version:}

Caterina Gozzi, Vasilis Dakos, Antonella Buccianti, Orlando Vaselli. Are geochemical regime shifts identifiable in river waters? Exploring the compositional dynamics of the Tiber River (Italy). Science of the Total Environment, 2021, 785, pp.147268. 10.1016/j.scitotenv.2021.147268 • hal-03373698

\author{
HAL Id: hal-03373698 \\ https://hal.science/hal-03373698
}

Submitted on 11 Oct 2021

HAL is a multi-disciplinary open access archive for the deposit and dissemination of scientific research documents, whether they are published or not. The documents may come from teaching and research institutions in France or abroad, or from public or private research centers.
L'archive ouverte pluridisciplinaire HAL, est destinée au dépôt et à la diffusion de documents scientifiques de niveau recherche, publiés ou non, émanant des établissements d'enseignement et de recherche français ou étrangers, des laboratoires publics ou privés. 


\title{
Can Geochemical Regime Shifts and Resilience be identified from Compositional Changes in Riverine Water?
}

\author{
Gozzi C. ${ }^{\mathrm{a}, *}$, Dakos V. ${ }^{\mathrm{b}}$, Buccianti A. ${ }^{\mathrm{a}, \mathrm{c}}$, Vaselli O., ${ }^{\mathrm{a}, \mathrm{c}}$ \\ ${ }^{a}$ University of Florence, Dept. of Earth Sciences, Via G. La Pira 4, 50121 Firenze, Italy; \\ ${ }^{b}$ ISEM, CNRS, Université de Montpellier, EPHE, IRD, 34095 Montpellier, France; \\ ${ }^{c}$ CNR-IGG Institute of Geosciences and Earth Resources, Via G. La Pira 4, 50121 \\ Firenze, Italy
}

\begin{abstract}
Rivers are dynamic and complex systems that constantly change their composition from sources to deltas. This is due to the influence of a set of variables controlled by hydro-litho-eco-atmospheric processes and anthropoclimate pressures which are, in turn, influenced by the catchment attributes. River water, compared to other environmental media, respond faster to disturbances, which are extensively and immediately reflected by the chemical composition of its waters. The paper explores the possibility to transpose the concept of ecological regime shift to river chemistry, by means of theoretical thoughts and a practical application to the case of the Tiber River (central Italy). Compositional Data Analysis (CoDA), robust Principal Component Analysis (PCA) and score-distance graphs were used to investigate data variability and the interlinks between response and forcing variables. The findings outline mechanisms and factors influencing the river self-restoring ability at a basin-wide scale, providing a better comprehension of the circumstances controlling the water system resilience, one of the major and most urgent challenges for the future of mankind.
\end{abstract}

Keywords: Regime shift, River chemistry, Environmental Science, Compositional Data Analysis

\footnotetext{
${ }^{*}$ Corresponding author, tel: +393394159892

Email address: caterinagozzi@unifi.it (Gozzi C.)
} 


\section{Introduction}

Natural systems characterized by non-linear dynamics do not always respond smoothly and regularly to changing external conditions, as widely verified across different research fields, e.g. ecology, climate science, medicine and economy (e.g. Andersen et al., 2008; Rodionov, 2004; Dakos et al., 2010; Hirota et al., 2011). An ever-growing research effort on the identification of thresholds and regime shifts has been done especially regarding a broad range of ecological systems, from marine environments to forests and lakes (e.g. Dayton, 1985; Naiman et al., 1988; Lees et al., 2006; Beaugrand, 2004). In ecology, a regime shift is defined as an abrupt status change in the ecosystem caused by passing a threshold where core ecosystem functions, structures and processes are radically changed (Andersen et al., 2008; Scheffer et al., 2012; Dakos et al., 2014). These ecological shifts are generally driven by external perturbations (e.g. climatic fluctuations, overexploitation, eutrophication) or by inner dynamics of the system (Andersen et al., 2008). This subject represents a growing scientific discipline which has not experienced any application to river geochemistry so far. In literature, only few research works are present addressing water system resilience issue, but all of them mainly focused on the hydrologic perspective, i.e. water-table variations and ground-surface water interactions (e.g. H. Fuchsa et al., 2018; de la Hera-Portillo et al., 2020). The basic ingredient for a regime shift is the presence of positive feedback which drives the system toward an alternative state (Angeli et al., 2004). Even though this principle is widely applied for simple isolated systems (Scheffer et al., 2012), its implementation to highly heterogeneous and complex systems represents a challenge to these 
days. In Earth Science, river catchments are an example of highly complex systems bearing properties such as self-organization, multi-scale variability, hydraulic and topographic gradients (Kleidon et al., 2013), patchiness, heterogeneity and feedback dynamics. These features together with litho-hydroeco-atmospheric processes and anthropo-climate pressures, jointly affect river water composition at various temporal and spatial scales. The knowledge of these complex interlinks plays a key role in both river basin management and water quality preservation from irreversible changes. The consequences of climate change will be immediately and sharply experienced by water, through significant modifications in water quantity, quality and distribution (WWF, 2019). The ever-growing population and its dependence on water for agriculture, transport, domestic, commercial and industrial activities is constantly increasing. Additionally, the demand for adequate water quality for domestic and health purposes will further increase for the prevention and mitigation of future pandemics (Cooper, 2020). Hence, water is an essential and defining element, a core variable in human and natural systems. As a consequence, the requirements for ensuring resilience in water systems should always guide trajectories and boundaries of human development (Boltz et al., 2019) and their understanding represents a key element for our future development. Since each river basin acts as a unique holistic system in tune with the climatic, geological and anthropogenic interactions, any study on the river system should consider river basin dynamics as a whole (Ramkumar et al., 2015). This implies the necessity to transcend subject barriers and to conduct interdisciplinary studies focused on basin-scale processes. Numerous researches suggest that the overall response of complex systems to changing 
conditions and perturbations depends on properties including heterogeneity of the components and their connectivity (e.g. Scheffer et al., 2012), revealing the importance of an extensive investigation on the nature of these interactions for river systems. The purpose of the paper is to verify whether an application of the ecological regime shift theory is possible for water chemistry. This hypothesis was tested for the surficial waters of the Tiber River (TR) in central Italy. The objective is to open up new avenues of research that might enable an enhanced prediction of the geochemical response of inland waters to environmental changes. The outcomes will be useful to define the critical/threshold limits that are able to guarantee the river system's self-restoration ability.

\section{Material and methods}

\subsection{Tiber River Basin overview}

The TR represents the seventh major contributing river to the Mediterranean Sea according to annual discharge $\left(240 \mathrm{~m}^{3} / \mathrm{s}\right)$ and its catchment is the largest of peninsular Italy $\left(17,375 \mathrm{~km}^{2}\right)$. TR has its source in the Mt. Fumaiolo at an altitude of 1,268 m and after flowing for $409 \mathrm{~km}$, it enters the Tyrrhenian Sea near Rome. During its course to the sea, five main tributaries (Paglia-Chiani and Treia on the right bank and Chiascio-Topino, Nera-Velino and Aniene on the left bank) flow into it (Fig. 1). The TRB falls within the administrative borders of six different Italian regions, but almost $90 \%$ of its surface is in Umbria and Lazio, whereas the remaining $10 \%$ is in Emilia Romagna, Tuscany, Marche and Abruzzo. The basin is located within the heterogeneous geological-topographical environment of central Italy and 
is defined by the following geomorphological boundaries: (i) the reliefs of Tuscan-Emilian Apennines towards N, (ii) the Umbrian-Marchean-Abruzzi Apennine ridge eastwards, (iii) Mt. Amiata (1,738 m), Sabatini, Vicani, Vulsini and Cimini mountains towards W and (iv) the Albani hills (956 m) southwards. The lithology varies from flysch sediments in the upper reaches, Apennine limestones to south-east and potassic and ultrapotassic volcanics towards south-west. The mean altitude is $520 \mathrm{~m}$ and only $6 \%$ of the total area of the basin exceeds 1,200 m, the highest peak being Mt. Velino (2,487 m), followed by Mt. Terminillo (2,213 m) and the Sibillini Mountains (Panichi et al., 2005). Land use in the basin is represented by agricultural areas (53\%), forests (39\%), urban areas, lakes and rock outcrops (5\%) (Iadanza and Napolitano, 2006). Lowlands, covering almost $15 \%$ of the basin, are mainly located in the low course of the TR and distributed around the urban area of Rome and the inter-montane basins (Sansepolcro, Gubbio and Foligno valleys and the Rieti and Terni depressions). The precipitation regime in the TRB is defined as sub-coastal (two precipitation minimum values in summer and winter) to marine (a summer minimum and a winter maximum value). The mean annual precipitation is about 1,200 $\mathrm{mm}$ and ranges from $700 \mathrm{~mm}$ at sea level to 2,000 mm along the central ridge (Bagnini et al., 2005). [Figure 1 about here.]

\subsection{The process of detecting regime shifts in river chemistry}

The process of identifying the presence of a geochemical regime shift (GRS) in water chemistry passes through the selection of potential environmental, anthropogenic and climatic drivers able to influence water compo- 
sition either in time or space. Nevertheless, this first step may be rather complicated by the large number of factors involved in the analysis and the high level of interconnection between them. This point gets often more difficult due to the lack of comprehensive data at an adequate scale. The second step is to identify the response variables that are to be considered for the monitoring of the evolution of riverine systems under changing conditions. From a geochemical point of view, the sentinel of the system state can be represented by the chemical composition of waters. Since the latter is made of several constituents (response variables), the state of the river can be monitored from different perspectives and at various scales by considering: (a) the water chemistry as a whole (e.g. Total Dissolved Solids), (b) major dissolves species, (c) nutrients, (d) pollutants or (e) minor and trace elements. This choice is crucial since environmental drivers can change significantly depending on the considered response variables. Hence, detecting regime shifts in a water system requires firstly the identification of the endogenous and exogenous variables influencing the system function (Boltz et al., 2019). The third step is to search for potential thresholds and tipping points driven by the interaction of those variables also considering the possibility of alternative systems states. The flip between different states in networks of populations, ecosystems or banks, is driven by the level of heterogeneity and connectivity of the system (Scheffer et al., 2012). Low connectivity coupled with high heterogeneity might cause the network to change gradually, rather than abruptly in response to changing conditions. On the contrary, homogeneous and highly connected networks try to resist the change until they reach a critical threshold for a systematic transition (Scheffer et al., 2012; Dakos 
et al., 2014, 2010). A stream network is made of nested structures characterized by a fractal geometry resulting in an apparently highly connected system, in which each branch converges in a grater one through a cascade process until reaching the river mouth (Rinaldo et al., 1993; Tarboton et al., 1988), as represented in the scheme of Figure 4. However, drainage divides separating each watershed provide a certain level of structural independence, a feature that can help to ensure a higher system resilience. In fact, feedback loops and connectivity trough the river network are possible only following the flow direction and adjacent watersheds cannot affect each other due to the presence of geomorphological boundaries. By contrast, in ecological systems interactions between neighbors are often possible in multiple directions, a feature that can lead to a domino effect and potentially critical transitions. Nevertheless, the inherent structure of the drainage network guarantees a certain grade of inner resilience mainly for the areas further upstream. Going downstream, the progressive mixing of heterogeneous waters having different geochemical origins and suffering multiple pressures is a complex factor that can trigger an abrupt compositional shift or provide a buffering effect through dilution processes.

An additional issue to be considered when determining a GRS in river chemistry is that most environmental pressures influencing river systems cannot be removed or altered to probe the system response. This technique is often used in laboratory tests to verify the answer of organisms to changing environmental conditions in order to predict critical limits for their survival (e.g. Griffiths and Philippot, 2013). This method is not directly applicable when considering complex river basins, nevertheless, an analogous approach 
could be used by comparing similar catchments with a great difference on the level of a single driver (e.g. mono-genetic vs geologically heterogeneous, natural- vs anthropic-dominated) or by likening geochemical data for the same basin at different spatial or temporal scales during which a variation of a certain external parameter is expected. In this research, we focused on possible basin-wide chemical variations induced by the spatial changes of some potential environmental drivers considering the intrinsically complex TRB catchment.

\subsection{River water dataset and drivers selection}

The geochemical dataset used in this work is part of the Ph.D. research conduct by Gozzi (2020), which involved a comprehensive survey on 222 surface waters within the TRB. As a first attempt, the possibility of a spatial Geochemical Regime Shift (GRS) was tested on the chemical composition of the main course of the Tiber River. Overall 38 water samples were considered for the analysis and were collected as follows: 19 during 2017 (13 in the High-Medium Tiber (HMT) during the winter time and 6 in the Low Tiber (LT) during summer) and 19 sampled during 2018 (6 in the LT during winter and 13 from the HMT during the summer). All samples were collected at a distance of about $20 \mathrm{~km}$ from one another, starting from the source area (Fig. 1). With the purpose of getting an overview on the hydrological conditions during the sampling time, TR hydrographs at the Ripetta flow gauge during 2017 and 2018 are shown in Figure 2a and 2b, respectively. Discharge data were kindly supplied by Regional Functional Centre - Lazio Region (2020). Mean daily discharges are highlighted in the graphs corresponding to spring and summer sampling days. The hydrographs show that samples 
refer, with a good approximation, to different flow conditions (high and low), although spread over two years (2017-2018). For each sample, major cations $\left(\mathrm{Ca}^{2+}, \mathrm{Mg}^{2+}, \mathrm{Na}^{+}, \mathrm{K}^{+}\right.$and $\left.\mathrm{NH}_{4}^{+}\right)$, anions $\left(\mathrm{Cl}^{-}, \mathrm{SO}_{4}^{2-}, \mathrm{F}^{-}, \mathrm{HCO}_{3}^{-}\right.$and $\left.\mathrm{NO}_{3}^{-}\right)$ and minor and trace species $\left(\mathrm{Mn}, \mathrm{Fe}, \mathrm{SiO}_{2}, \mathrm{Sr}, \mathrm{Rb}, \mathrm{Ba}\right.$ and $\left.\mathrm{B}\right)$, were considered for the GRS analysis. $\mathrm{Br}^{-}$and $\mathrm{PO}_{4}^{3-}$ species as well as $\mathrm{Ni}, \mathrm{Co}, \mathrm{Cu}$ and Zn were not included in the analysis because the percentage of values below the lower detection limit (LDL) was higher than $40 \%$ of the total number of observations. The few remaining values below the LDL were replaced by $2 / 3$ of the detection limit (Martín-Fernández et al., 2003). Major species enable the identification of the main hydrochemical facies of the water, revealing the origin of solutes and evolutionary processes. Conversely, the concentration of trace elements in surface water more often depends on changing geochemical conditions, such as pH and redox conditions, which influence their presence or removal from the water column. Therefore, it is important to evaluate the response of water chemistry considering both the hierarchical levels of the composition. Further details regarding sampling and analytical methods are given in Gozzi (2020).

The drainage area was estimated from the Digital Elevation Model (DEM) and was therefore used as a core variable for the evaluation of the selected forcing parameters. For each watershed, sampling sites define the outlets of each contributing area, which is expected to influence the chemical composition of the respective water sample along the main course (Fig. 1). The DEM was obtained from Copernicus Land Monitoring Service (2019b) (EU-DEM version 1.1, zone E40N20; $25 \mathrm{~m}$ resolution) and then resampled to a lower resolution of $100 \mathrm{~m}$ for better handling and faster processing. The hydrologic 
analysis was performed using the Spatial Analyst and the Hydrology Tool present in ArcGIS. Once delineated the 19 watersheds and their drainage divides, the following landscape properties were estimated: drainage area (ha), mean elevation $(\mathrm{m})$ and slope $\left({ }^{\circ}\right)$. The latter were obtained considering not only the calculated basins but all the nested watersheds contributing to the selected outlets. For the estimation of the human impact for each basin, the Global Human Influence Index Dataset of the Last Wild Project, Version 2, 2005 (LWP-2) was used. The index produced by Wildlife Conservation Society and Center for International Earth Science Information Network Columbia University (2005) is a global dataset of 1-kilometer grid cells, created from nine global data layers covering human population pressure (population density), human land use and infrastructure (built-up areas, nighttime lights, land use/land cover), and human access (coastlines, roads, railroads, navigable rivers). Precipitation data were downloaded from WorldClim 2.0 Beta version 1 (June 2016), where average monthly climate data are available as GeoTiff files for the period 1970-2000 (Fick and Hijmans, 2017). Mean rainfall was estimated for each area using ArcGIS considering the month corresponding to each sampling campaign. Land cover and main lithotypes layers were derived from Copernicus Land Monitoring Service (2019a) and ISPRA Ambiente (2017), respectively. Due to the high number of classes representing different lithotypes and soil use compared to the number of water samples, only the most relevant variables were considered for the GRS analysis. The latter were chosen based on their importance with reference to the total drainage area. In accordance with the stream-graphs represented in Figure 3, sand-silicatic sequences and carbonatic rocks were considered as 
main geological drivers while forests and arable lands as land use ones.

[Figure 2 about here.]

[Figure 3 about here.]

\subsection{Compositional methods: the solution for an holistic approach}

In Geosciences, problems involving compositional data, such as spurious correlations, negative bias, subcompositional incoherence and constrained sample space are well known in literature starting from Aitchison (1982). A reliable analysis of geochemical data should take into consideration their compositional nature. The Compositional Data Analysis Approach (CoDA) starts from the assumption that it is the relative variation of chemical components the matter of interest, rather than the absolute one (Pawlowsky-Glahn and Egozcue, 2006; Buccianti et al., 2006). Relative behavior means that the information lies in the ratios between the components, not in the absolute values (Pawlowsky-Glahn and Egozcue, 2020). Besides, as highlighted by Gozzi et al. (2019, 2020), the CoDA approach provides the possibility to study a chemical composition as a whole leaving aside the investigation of single variables. This holistic aspect is fundamental for the detection of possible regime shifts in riverine chemistry since it enables to investigate simultaneous interactions among water constituents and the complex surrounding environment. A solution to deal with CoDa is expressed by the principle of working on coordinates (Pawlowsky-Glahn and Buccianti, 2011). Compositional data can be transformed into new real coordinates by means 
of transformations, thus allowing the use of classical statistical and geostatistical methods without any further issue. In this research, the centered log-ratio (clr) transformation was applied. It consists of dividing each component $\mathrm{x}_{i}$ by the geometric mean $\mathrm{g}(\mathbf{x})$ of all the considered parts, represented, in our case, by the chemical species. The related complete formula is shown in Equation (1):

$$
\operatorname{clr}(\mathbf{x})=\left(\ln \frac{x_{i}}{\mathrm{~g}(\mathbf{x})}\right)_{i=1, \ldots, D} \quad \text { with } \quad \mathrm{g}(\mathbf{x})=\sqrt[D]{x_{1} \cdot x_{2} \cdots x_{D}}
$$

As a result, the obtained crl-coordinates contain within themselves the information about the interlinks between each element and the barycentre of the entire composition.

\subsubsection{Robust $P C A$ and analysis of $P C$ s spatial series}

Clr-transformed data were used to create robust compositional biplots investigating $\mathrm{TR}$ data variability for the different sampling periods. The $\mathrm{R}$ package Robcompositions (Templ et al., 2011) was used to perform a robust PCA in a compositional context. The obtained scores and loadings were then used as input factors within the $\mathrm{R}$ package Factoextra (Kassambara and Mundt, 2019) which provides more effective graphical tools to display the PCA results. Among these, particularly effective is the possibility to color PCs scores according to the value of an additional variable. This was used to perform a first exploratory analysis to verify potential associations between water chemistry variability and the magnitude of different environmental drivers. Successively, to better evaluate the linkages between water compositions and forcing factors the following steps were performed. First, PCA 
was run for major, trace elements and drivers separately (Martín-Fernández et al., 2018). Secondly, chemical PCs scores were plotted together with driver scores versus the distance from the source area. All scores were normalized to have mean 0 and standard deviation (sd) 1 using the scale function in $\mathrm{R}$ for an easier comparison. Before performing the PCA, the driver dataset was also rescaled to make data comparable with each other. The target is to verify the presence and spacing of a potential GRS along the TR and define the main chemical response variables (crl-coordinates) and environmental pressures characterizing each regime. This approach is similar to that used by Mollmann et al. (2009) in time series of ecological parameters for the Central Baltic Sea. Nevertheless, herein it is implemented for spatial data with new graphical-numerical tools which includes a compositional approach.

[Figure 4 about here.]

\section{Results}

\subsection{Response variables: major and trace species variability}

In this Section the results of the robust compositional PCA for the TR waters are described. In Figure 5 the resulting clr-biplot for major elements is shown, together with the loading plots of the first two components. Scores are colored according to the sampling time, while symbols mark the different location (HMT or LT). The variable labels (e.g. $\mathrm{Cl}^{-}, \mathrm{SO}_{4}^{2-}$ ) in the plot represent the clr transformed data of the corresponding species. Most of the clr-variance is accounted by the first dimension with $71 \%$ of the total variability, the second dimension explaining only $14 \%$. 
[Figure 5 about here.]

In the covariance biplots, rays length is proportional to the variability of the clr-variable and the attention is mainly focused on the links between the vertices of the rays (Daunis-I-Estadella et al., 2006). On the first component, $\mathrm{NO}_{3}^{-}, \mathrm{NH}_{4}^{+}, \mathrm{K}^{+}$, and $\mathrm{Cl}^{-}, \mathrm{Na}^{+}, \mathrm{SO}_{4}^{2-}$ log-ratios, having positive and negative loadings, respectively, are well represented in the projection and their rays are almost collinear. These variables are the ones showing the highest variability. On the second dimension, the largest contribution is provided by $\mathrm{F}^{-}$ log-ratio, while $\mathrm{Ca}^{2+}, \mathrm{Mg}^{2+}, \mathrm{HCO}_{3}^{-}$exhibit shorter rays and tight links, showing a similar pattern of variability. On the clr-biplot, links between the rays $\mathrm{Na}^{+}-\mathrm{F}^{-}$and $\mathrm{F}^{-}-\mathrm{NO}_{3}^{-}$are orthogonal, thus indicating a low correlation for the corresponding clr-variables. The biplot highlights the different log-ratio associations characterizing the composition of the river stretches (HMT and LT) under varying hydrologic conditions. In particular, it may be observed that the importance of N-bearing species in relation to the compositional barycenter increases in the HMT and especially during the drought period. On the other hand, the association of $\mathrm{Cl}^{-}, \mathrm{Na}^{+}, \mathrm{SO}_{4}^{2-}$ clr-variables mark the lower reaches of the river, with higher relative increments during the dry season. The obtained PCs scores were then colored according to the magnitude of the main drivers, also including the drainage area. The outcomes for morphological, land use and geo-climatic parameters are displayed in Appendix 1 as supplementary materials (Figs. A.1, A.2, A.3, respectively). The outcomes reveal interesting patterns and possible environmental-chemical correlations, which deserve to be further investigated by means of a joint analysis.

The robust clr-biplot for minor and trace (s.l. trace) elements jointly with 
the corresponding loading plots is shown in Figure 6. It accounts for the $85 \%$ of the overall variability, $54 \%$ on the first and $31 \%$ on the second dimension, respectively.

[Figure 6 about here.]

The PCs projection well represents the Fe, $\mathrm{Rb}$ and $\mathrm{Ba}$ log-ratios which show the longest rays and higher variability, while $\mathrm{Sr}$ and $\mathrm{SiO}_{2}$ are not properly rendered. Even in this case, all groups seem to stand out, with B and Rb log-ratios mainly dominating in LT while those of Fe, Mn and B characterizes the upper reaches.

\subsection{Forcing variables: environmental drivers variability}

The robust biplot for the selected drivers jointly with the corresponding loading plots is shown in Figure 7. In this case, the interpretation of the biplot follows classical rules, since we deal with non-compositional variables. The plot explains about $88 \%$ of the total variability, the first and the second dimension accounting for $70 \%$ and $18 \%$, respectively.

[Figure 7 about here.]

Drivers' variability on the first component is mainly guided by geo-climatic factors: sand-silicatic sequences and rainfall are predominant in HTM (negative scores), while carbonatic lithotypes characterize the LT area (positive scores). The right shift of PC scores during drought conditions reflects the difference in precipitations values since other parameters do not change depending on the season. Considering the second component, arable lands and 
HII on positive loadings oppose to forests, slope and elevation factors on negative ones, thus highlighting the different dominating features for the upper (nos. 1-8, 20-27) and medium (nos. 9-13, 28-32) TR.

\subsection{Linking response and forcing variables: distance-PCs graphs}

In this section, PCs scores for response and forcing variables are plotted together versus the distance from the TR source to detect the presence and spacing of a potential GRS. Hereinafter, for the sake of clarity, chemical PC1 scores of major species are called Chemical Index 1 (Ch1) while those of minor and trace elements, Trace Chemical Index 1 (TCh1) and likewise PC2 scores (Ch2 and TCh2). Similarly, drivers PC1 and PC2 scores are named Forcing Index 1 (Fc1) and Forcing Index 2 (Fc2), respectively.

In Figure 8(a,c) distance-PCs graphs are shown for major compounds in the two different hydrological conditions.

[Figure 8 about here.]

The Wald-Wolfowitz Runs Test (Wald and Wolfowitz, 1940) performed for all indexes reveals that the data are not random ( $\mathrm{p}$-value $<0.05)$, and the Augmented Dickey-Fuller test (Fuller, 1996) indicates that the sequences are not stationary ( $\mathrm{p}$-value $>0.05$, null hypothesis accepted). Along the HMT, Ch1 generally show positive scores, indicating the relative dominance of $\mathrm{NO}_{3}^{-}, \mathrm{NH}_{4}^{+}, \mathrm{K}^{+}$species. In this area, only a couple of negative values are detected just after the river source during flood conditions, thus suggesting a greater contribution of $\mathrm{Cl}^{-}$and $\mathrm{Na}^{+}$. Downstream, an abrupt negative compositional shift (predominance of $\mathrm{Cl}^{-}, \mathrm{Na}^{+}$and $\mathrm{SO}_{4}^{2-}$ ) is detected at $248 \mathrm{~km}$, once Nera waters enter the main course, as also shown by Gozzi et al. (2019) 
by means of the robust pairwise Mahalanobis distance. Successively, values seem to slightly increase for the next sampling point, in particular during high flow periods, stabilizing afterwards. After a remarkable change next to the source, Fc1 exhibits an overall ascending trend featured by a step-wise behavior with three different steps in both cases (Fig. 8 a, c). The pattern of Fc1 mainly represents the gradual change geo-climatic drivers, starting from a dominance of sand-silicatic and rainfall in the HMT (negative scores) to carbonate rocks in the LT (positive scores) (see also Fig. 7). In the lower plots (Fig. 8 b, d), deviations from median values of the indexes along the river course are represented, as a robust measure of change from the barycenter. The two bar-plots help to more easily identify potential bonds between response and forcing variables. Looking at deviations on the HMT, no clear interlink between the two indexes can be noticed, even if both of them generally increase going downstream. On the contrary, in the LT, the change from positive to negative deviations of $\mathrm{Ch} 1$ exactly matches the variation from negative to positive ones of Fc1, and this association is kept up to the river mouth.

Since even small changes of external parameters can yield non-linear response of the system, analogous distance-PCs graphs were also created which compare Ch1 to Fc2 (Fig. 9 a-c).

[Figure 9 about here.]

Fc2 also shows a step-like behavior changing from a major influence of slope, forests and elevation parameters (negative scores) in the upper reaches, to dominance of HII and arable lands in the Medium Tiber (positive scores) and 
to values close to the median on the last river stretch (see also Fig. 7). In the early course, during flood conditions Ch1 and Fc2 exhibit a similar behavior, suggesting a possible mutual interlink (Fig. 9a). Conversely, during summer, Ch1 is more stable near the source, but then it also increases (dominance of $\mathrm{NO}_{3}^{-}, \mathrm{NH}_{4}^{+}$and $\mathrm{K}^{+}$) when the pressure of $\mathrm{HII}$ and arable land rises relatively to forest and morphological parameters (Fig. 9c). In the LT, deviations of Fc2 from the median are low compared to the remarkable changes monitored by Ch1 (Fig. 9b-c), which means a poor interconnection. Herein, we mainly focus on Ch1, since it accounts for the majority of the chemical variability, but additional distance-PCs graphs for Ch2 are illustrated in Figures S.4S.5 (Supplementary Materials). Once explored the river chemistry from the perspective of its major compounds, we then looked into the composition in terms of its minor and trace elements, which represent one of the main sources of pollution in the aquatic environment. TCh1 and Fc1 are compared versus the distance from the source in Figure 10, jointly with the bar-plots indicating the respective deviations from their median values.

[Figure 10 about here.]

Similarly, statistical tests reveal that data sequences are neither random nor stationary, but characterized by spatial trends along the river path. TCh1 exhibits negative scores (dominance of $\mathrm{Fe}, \mathrm{Ba}$ and $\mathrm{Mn}$ ) in the upper-course followed by a transition period with values close to the medians and then positive scores in its lower part (dominance of Rb and B). TCh1 behavior is overall cumulative with some small fluctuations, especially when moving to the LT (Fig. 10a,c). The pattern appears to be gradual never showing sudden 
changes. Nevertheless, a possible turning point can be placed at $203 \mathrm{~km}$, in correspondence of the transition between HMT and LT, which also matches the occurrence of volcanic formations (Fig. 3). Comparing the two hydrologic conditions, TCh1 shows bigger deviations from the median in the HMT during high discharge periods (Fig. 10b) with respect to the corresponding plot for the dry season (Fig. 10d). Geo-climatic drivers (Fc1) seem to reflect fairly well the global evolution at basin-scale of the composition in terms of the higher trace elements variability with only a few differences. Considering the lower variability, TCh2 displays a stable trend with only some chemical changes approaching the river mouth and poor interconnections with the considered forcing factors (Fig. S6, Supplementary Materials). For further details regarding other combinations of indexes for trace elements refer to Supplementary Materials.

\section{Discussion}

\subsection{Geochemical response of TR waters to environmental changes}

The robust PCA enabled to pull out the most relevant chemical and forcing variables dominating TR variability, also considering the river chemistry from an holistic point of view by means of the CoDA approach. Figure 5 gives prominence, on the first dimension, to two different associations of clrvariables $\left(\mathrm{NO}_{3}^{-}, \mathrm{NH}_{4}^{+}, \mathrm{K}^{+}\right.$vs Cl- $\mathrm{Na}^{+}, \mathrm{SO}_{4}^{2-}$ ) that describe a great amount of variability (about 70\%). Considering PC1, the barycenter of the biplot separates HMT waters dominated by N-bearing species from those from LT having a major sodium-chlorinated contribution. The analysis of the joint behavior of Ch1 and Fc1 (geo-climatic drivers) (Fig. 8a-d), reveals a match 
between the abrupt shift towards a sodium-chlorinated feature of Ch1 and the variation of $\mathrm{Fc} 1$ from a dominance of sand-silicatic sequences and rainfall to that of carbonate rocks. Hence, the increasing portion of the watershed covered by carbonatic lithotypes belonging to the Appennine Ridge (Nera sub-basin) seems to determine the relative increase of $\mathrm{Cl}^{-}, \mathrm{Na}^{+}$and $\mathrm{SO}_{4}^{2-}$ in TR waters. From a geochemical perspective, this interlink is apparently unclear since the interaction with carbonatic rocks is expected to provide a major relative contribution of $\mathrm{Ca}^{2+}, \mathrm{HCO}_{3}^{-}$ions. Nevertheless, the knowledge of the underlying geological substratum associated with the carbonate domain and the predominance in the area of infiltration over run-off processes (Boni et al., 1986), help to explain the reason for the obtained association. In fact, the chemical change can be understood by considering the role of groundwater circulation and more specifically the important input of the high-pCO2, high-salinity springs such as those of Stifone-Montoro (e.g. Boni et al., 1986) located by the Nera river gorge. These high flow rate springs $\left(15 \mathrm{~m}^{3} / \mathrm{s}\right)$ are fed by water circulating in the Narni-Amelia regional aquifer system and reacting with the hosting rocks, mainly consisting of dolostones, limestones and evaporites (Frondini et al., 2012). This sub-surface water-rock interaction sharply increases the salinity of Nera waters and determine the shift towards a sodium-chlorinated composition of TR after the confluence with the tributary. As a result, it is possible to assume that the Ch1-Fc1 association defines LT chemistry as mainly guided by a natural geochemical process induced by the changing pressure of geo-climatic drivers. Instead, these drivers seem to play a more marginal role in conditioning the composition of HMT river waters. The analysis of the joint behavior of Ch1 and 
Fc2 (Fig. 10) explore the influence of the lower part of the drivers' variability (holding both morphological and land use pressures) on the higher part of the chemical one. In the early the TR course, there is a slight relative increase of $\mathrm{Cl}^{-}, \mathrm{Na}^{+}$which appear to be linked with a higher impact of slope, forests, and elevation pattern (Fig. 10a) as well as with sand-silicatic sequences and rainfall according to Fc1. This behavior might be due to the major contribution of rainfall to the river flow in the steep mountainous area during winter-spring, leading to a higher relative amount of $\mathrm{Cl}^{-} \mathrm{Na}^{+}$derived from marine inputs in rainwater. This hypothesis is supported by the different response of Ch1 in the upper reaches during flood and drought conditions (Fig. 10a,c), the latter being more stable and thus less influenced by morphological and climatic drivers described by Fc1 and Fc2.

Going downstream, N-bearing species dominates the HTM composition, until the above-mentioned tipping point occurring at $248 \mathrm{~km}$, after the confluence with the Nera river. Ch1 and Fc2 exhibit a similar behavior, suggesting a potential linkage with the increasing pressure, on the corresponding drainage area, of arable lands and HII. The dominance of the association of $\mathrm{NO}_{3}^{-}, \mathrm{NH}_{4}^{+}$, and $\mathrm{K}^{+}$clr-variables can be the result of diffuse inputs from urban and agricultural areas or animal husbandry practices (Meybeck, 1982; Peierls et al., 1991; Deutsch et al., 2006; Harrison et al., 2019). Therefore, the Ch1-Fc2 association enabled to define two main geochemical-environmental interaction processes characterizing the HTM: a first one of natural origin mainly guided by morphological features and dependent on seasonal variations, and a second one, largely influenced by the pressure of anthropic activities on TRB territory. Differently, Fc2 is not able to explain the shift of Ch1 in the LT 
which is mainly related to Fc1 (geo-climatic drivers). In fact, Figure 10b,d) highlights that $\mathrm{Fc} 2$ deviations from the medians are almost null both at the beginning and for the entire spacing of the compositional change.

Turning to consider trace elements, we evaluate a response variable that represents a different hierarchical level of the water composition. TCh1 smoothly reflects the variations of the $\mathrm{Fc} 1$ and consequently the changing proportion of lithotypes in the drained area. Fe, $\mathrm{Mn}$, and $\mathrm{Ba}$ log-ratios dominance in the HMT can be the result of weathering processes of terrigenous deposits. Differently, LT is mainly typified by Rb and B log-ratios stemming from water-rock interaction processes with potassic and ultra-potassic volcanic complexes of the Vulsini, Cimini and Sabatini districts and by a possible influence of the hydrothermal springs located by the Aniene river course (e.g. Acque Albule and Salone-Acqua Vergine).

\subsubsection{What is that makes a common chemical change a GRS?}

Once marked out the geochemical response to the spatial variation of the selected external agents, the target was to understand if a GRS can be considered as a possible feature for the TR or more broadly for water systems. Among the observed variations the abrupt change detected by Ch1 could represent a possible GRS since it meets the following requirements: i) it represents a relevant and sudden chemical change; ii) the new chemical state is maintained in space and time (different seasons); iii) the shift is driven by the change of an environmental pressure; iv) the new condition appears irreversible and affect the self-healing function of TR waters. One of the key issues is to explain why after the geologically-induced shift, the composition is not able to restore itself to previous conditions. From the geochemical 
perspective the ratio between the discharges of the TR before and after the confluence with the Nera river, drastically influences the concentrations of $\mathrm{Cl}^{-}, \mathrm{Na}^{+}, \mathrm{SO}_{4}^{2-}$ measured after the mixing point. This factor determines the magnitude of the shift compared to the compositional barycenter. Nevertheless, once the composition is shifted to the new state, the system shows a small level of restoration capacity, which appears to be slightly influenced by the different flood conditions (Fig. 8). This can be linked to the catchment properties and particularly to the lower connectivity during summer due to less water supply from the surrounding areas. Moreover, it is important to consider that the upper reaches of the TR are characterized by a torrential and turbulent regime, whereas the end course, after the confluence with the Nera river, is featured by a slow and meandering flow as a result of the decreasing elevation. These features can also influence the restoring capacity of the river after the change. In fact, in low flow rate zones, sedimentation prevails upon erosional processes generating lower connectivity and weaker ground-surface water interchanges with respect to the upstream areas. Nevertheless, the absence of pressures from positive buffering drivers for the water quality such as rainfall and forested lands can also have a role in the observed pattern. The conservative nature of $\mathrm{Cl}^{-}$and $\mathrm{Na}^{+}$elements and the presence of geochemical barriers avoiding precipitation also contribute maintaining the new chemical state to the river mouth. From this perspective, it is possible to state that a GRS exists along the Tiber river course. The latter represents not just an important geochemical change monitored by a shift in dominant solutes with respect to the compositional barycenter of the waters, but also a change that is spatially conserved by means of the 
joint effect of several endogenous and exogenous environmental factors and catchment attributes. These influencing agents consist of geochemical properties of the solutes, least rainfalls, changed land use from forest- to human impact- dominated, lower connectivity, surficial-ground water interchanges and seasonal effects. Trace elements pattern show modularity gradually adjusting themselves to changes, thus indicating a higher adaptive capacity of the system to perturbations. This behavior could be linked to the greater trace elements affinity to the solid phase. In fact, they can easily precipitate under varying Eh-pH conditions and can therefore be removed from the aqueous phase and get sequestered in stream sediments (Kabata-Pendias, 2015). The results obtained by the practical example of the TR flow highlighted the concept that considering a change in a single external agent is often not sufficient to explain the water chemistry variations which are the results of a complex environment acting in tune. Nevertheless, the proposed approach could represent a starting point for the analysis of the water chemistry from a new holistic perspective.

\section{Conclusions}

Due to the extreme importance of river water for human and natural systems, transcending subject barriers and analyzing rivers from a holistic and interaction-based point view is crucial to understand the complexity of basin-wide processes. This work, even though considering a limited amount of data, attempted to understand the connections between the TR composition and the spatial changes of some potential environmental pressures. The robust PCA investigated relevant compositional and forcing variables while 
distance-PCs graphs highlighted their potential interlinks, thus providing an enhanced prediction of the geochemical response of the TR waters to environmental changes (e.g. pollution or climatic extremes events) The main conclusions of the research are summarized in the following points:

- HMT is the river stretch more resilient to changes. Its lower chemical variability in the early course is mainly associated with morphological drivers (i.e. forests, slope and elevation), and in the middle course the increasing pressures of arable lands and HII are not able to affect significantly the composition of its water.

- Differently, a GRS was detected in LT waters as a result of an important geochemical change in its main species with reference to the compositional barycenter. The new chemical state is spatially maintained thanks to the joint effect of different drivers and catchment properties, reveling a low resilience of the LT to external perturbations. In this case, the abrupt change in the water system is triggered by a single driver, but the subsequent interactions with the surrounding environment (land use, morphology, climate and HII) are those that actually defined the change as a GRS.

- Drought conditions generally increase TR water variability in the LT and are able to influence the restoration capacity of the system. This implies that the greater severity of droughts periods induced by climate change represents a threatening factor for TR water self-restoring ability. On the contrary, rainy periods appear to have a major influence on the chemical variability of the early TR course. 
- The outcomes also revealed that major and trace dissolved species respond in a different way to external changes, representing, for the aqueous phase, the lesser and the major resilient portion of the composition, respectively.

The natural extension of this research will be focused not only on the main TR course but on the entire catchment, considering the entire dataset of 222 river waters which includes major, minor tributaries and streams. This will enable to encompass a larger number of drivers (e.g. morphometric indexes, run-off, discharge, connectivity) for a more comprehensive assessment of the mutual relationships between river chemistry and environmental pressures. Under this condition, further investigations will be possible on the interlinks between the river basin structure and its energy through the evaluation of its thermodynamic properties. In fact, river systems have an inherent supply of potential energy driven by topographic gradients which is expressed and dissipated in many different ways, such as the creation of complex tree-like drainage networks (Kleidon et al., 2012, 2013).

In conclusion, this research represents the first effort in literature to understand and transpose the ecological approach of regime shift detection to river geochemistry. Even if with some differences and difficulties, an application to river chemistry is possible and represents an interesting path of research. The recent COVID-19 pandemic highlighted the importance of using holistic methods for an enhanced knowledge of the resilience of the natural environment. Deterioration of riverine water quality due to natural/anthropogenic impacts is linked to ecosystem degradation, loss of biodiversity and therefore human health. As a result, one of the most urgent challenges for the future of 
mankind is to find out, despite the uniqueness of each river basin, universal mechanisms and natural laws able to preserve water system resilience.

\section{Acknowledgements}

The University of Florence is acknowledged for the financial support to the present research through University (A.B) and Laboratory of Stable Isotopes (O.V.) funds. Tuscany Region (Italy) is thanked for funding the three-year Ph.D. scholarship. Institut de Sciences de l'Evolution de Montpelier of the Université de Montpellier (ISEM) is also acknowledged for the valuable collaboration.

\section{References}

Aitchison, J., 1982. The Statistical Analysis of Compositional Data. Journal of the Royal Statistical Society Series B 44(2), 139-177.

Andersen, T., Carstensen, J., Hernandez-Garcia, E., Duarte, C., 2008. Ecological thresholds and regime shifts: approaches to identification. Trends in Ecology and Evolution 24, 49-57.

Angeli, D., Ferrell Jr., E., Sontag, E., 2004. Detection of multistability, bifurcations, and hysteresis in a large class of biological positive-feedback systems, in: Proc. Natl. Acad. Sci. U.S.A., p. 1822.

Bagnini, S., Bruschi, S., Castellano, F., Colatosti, G., Gatta, L., Malvati, P., Moretti, D., Ruisi, M., Terranova, I., Traversa, P., Vitale, V., Villani Conti, C., Verga, V., 2005. Tevere Pilot River Basin Article 5 Report: pursuant to the water framework directive. Gangemi Editore spa, Roma, 175pp. 
Beaugrand, G., 2004. The North Sea regime shift: evidence, causes, mechanisms and consequences. Progress in Oceanography , 245262doi:10.1016/j.pocean.2004.02.018.

Boltz, F., Poff, N., Folke, C., Kete, N., Brown, C., Freeman, S., Matthews, J., Martinez, A., Rockström, J., 2019. Water is a mater variable: Solving for resilience in the modern era. Water Security 8.

Boni, C., Bono, P., Capelli, G., 1986. Hydrogeological scheme of central Italy. Memories of the Italian Geological Society 35, 991-1012. [in Italian].

Buccianti, A., Mateu-Figueras, G., Pawlowsky-Glahn, V., 2006. Compositional Data Analysis in the Geosciences: From Theory to Practice. volume 264(1-10). Geological Society, London, Special Publications, 207pp.

Cooper, R., 2020. Water Security beyond Covid-19. Technical Report. Brighton, UK: Institute of Development Studies.

Copernicus Land Monitoring Service, 2019a. Corine land cover. URL: https://land.copernicus.eu/pan-european/corine-land-cover/clc2018.

Copernicus Land Monitoring Service, 2019b. EUDEM Digital Surface Model. URL: https://land.copernicus.eu/imagery-in-situ/eu-dem/eu-dem-v1.1.

Dakos, V., Carpenter, S., van Nes, E., Scheffer, M., 2014. Resilience indicators: prospects and limitations for early warnings of regime shifts. Philosophical Transactions of the Royal Society B 370(20130263), 1-10.

Dakos, V., van Nes. E.H., Donangelo, R., Fort, H., Scheffer, M., 2010. Spatial correlation as leading indicator of catastrophic shifts. Theoretical Ecology 177(3), $163-174$. 
Daunis-I-Estadella, J., Barceló-Vidal, C., Buccianti, A., 2006. Exploratory compositional data analysis. Geological Society, London, Special Publications 264(1), $161-174$

Dayton, P., 1985. Ecology of kelpt communities. Annu.Rev.Ecol.Syst. 16, 215-245.

Deutsch, B., Mewes, M., Liskow, I., Voss, M., 2006. Quantification of diffuse nitrate inputs into a small river system using stable isotopes of oxygen and nitrogen in nitrate. Organic Geochemistry 37, 1333 - 1342. doi:https://doi.org/10.1016/j.orggeochem.2006.04.012.

Fick, S., Hijmans, R., 2017. Worldclim 2: New 1-km spatial resolution climate surfaces for global land areas. International Journal of Climatology .

Frondini, F., Cardellini, C., Caliro, S., G. Chiodini, G., Morgantini, N., 2012. Regional groundwater flow and interactions with deep fluids in western Apennine: the case of Narni-Amelia chain (Central italy). Geofluids 12, 182-196.

Fuller, W.A., 1996. Introduction to Statistical Time Series. second ed. ed., New York: John Wiley and Sons.

Gozzi, C., 2020. Weathering and transport processes investigated through the statistical properties of the geochemical landscapes: the case study of the Tiber river basin (Central Italy). Ph.D. thesis. University of Pisa, Department of Earth Sciences.

Gozzi, C., Filzmoser, P., Buccianti, A., Vaselli, O., Nisi, B., 2019. Statistical methods for the geochemical characterisation of surface waters: The case study of the Tiber River basin (Central Italy). Computers and Geosciences 131, 80-88. 
Gozzi, C., Sauro Graziano, R., Buccianti, A., 2020. Part-Whole Relations: New Insights about the Dynamics of Complex Geochemical Riverine Systems. Minerals 10. doi:doi:10.3390/min10060501.

Griffiths, B.S., Philippot, L., 2013. Insights into the resistance and resilience of the soil microbial community. FEMS Microbiology Reviews 37, 112-129. doi:10.1111/j.1574-6976.2012.00343.x.

H. Fuchsa, E., C. Carrollb, K., P. King, J., 2018. Quantifying groundwater resilience through conjunctive use for irrigated agriculture in a constrained aquifer system. Journal of Hydrology 565, 747-759.

Harrison, S., McAree, C., Mulville, W., Sullivan, T., 2019. The problem of agricultural 'diffuse' pollution: Getting to the point. Science of The Total Environment 677, 700 - 717. doi:https://doi.org/10.1016/j.scitotenv.2019.04.169.

de la Hera-Portillo, A., López-Gutiérrez, J., Zorrilla-Miras, P., Mayor, B., LópezGunn, E., 2020. The Ecosystem Resilience Concept Applied to Hydrogeological Systems: A General Approach. Water 12. doi:doi:10.3390/w12061824.

Hirota, M., Holmgren, M., H. Van Nes, E., Scheffer, M., 2011. Global Resilience of Tropical Forest and Savanna to Critical Transitions. Science 334, 232-235. doi:10.1126/science.1210657.

Iadanza, C., Napolitano, F., 2006. Sediment transport time series in the Tiber River. Physics and Chemistry of the Earth 31, 1212-1227.

ISPRA Ambiente, 2017. Geoportale Ispra Ambiente. URL: http://geoportale.isprambiente.it/sfoglia-il-catalogo/?lang=en.

Kabata-Pendias, A., 2015. Trace Elements in Abiotic and Biotic Environments. CRC Press, Taylor and Francis Group, 458 pp. 
Kassambara, A., Mundt, F., 2019. factoextra: Extract and Visualize the Results of Multivariate Data Analyses. URL: https://CRAN.R-project.org/package=factoextra. $R$ package version 1.0.6.

Kleidon, A., Zehe, E., Ehret, U., Scherer, U., 2012. Thermodynamics, maximum power, and the dynamics of preferential river flow structures on continents. Hydrol. Earth Syst. Sci. Discuss. 9. doi:doi:10.5194/hessd-9-7317-2012.

Kleidon, A., Zehe, E., Ehret, U., Scherer, U., 2013. Thermodynamics, maximum power, and the dynamics of preferential river flow structures at the continental scale. Hydrology and Earth System Sciences 17, 225-251.

Lees, K., Pitois, S., Scott, C., Frid, C., Mackinson, S., 2006. Characterizing regime shifts in the marine environment. Fish Fish. 7, 104-127.

Martín-Fernández, J., Barceló-Vidal, C., Pawlowsky-Glahn, V., 2003. Dealing with Zeros and Missing Values in Compositional Data Sets. Mathematical Geology $35(3), 253-278$.

Martín-Fernández, J.A., Olea, R.A., Ruppert, L.F., 2018. Compositional Data Analysis of Coal Combustion Products with an Application to a Wyoming Power Plant. Mathematical Geosciences 50, 639-657.

Meybeck, M., 1982. Carbon, nitrogen, and phosphorus transport by world rivers. American Journal of Science 282, 401-450. doi:10.2475/ajs.282.4.401.

Mollmann, C., Diekmann, R., Muller-Karulis, B., Kornilovs, G., Plikshs, M. Axe, P., 2009. Reorganization of a large marine ecosystem due to atmospheric and anthropogenic pressure: a discontinuous regime shift in the Central Baltic Sea. Global Change Biology 15, 1377-1393. 
Naiman, R., Johnston, C., Kelley, J., 1988. Alteration of North-American streams by beaver. Bioscience 38, 753-762.

Panichi, C., Giuliano, G., Preziosi, E., Gherardi, F., Droghieri, E., 2005. Hydrochemical and Isotopic Characterisation of the Base Flow in the Tiber Basin. Relations between Surface Waters and Groundwaters. volume 124. Romana Editrice, 113pp.

Pawlowsky-Glahn, V., Buccianti, A., 2011. Compositional Data Analysis: Theory and Applications. John Wiley \& Sons Ltd., 400pp.

Pawlowsky-Glahn, V., Egozcue, J., 2006. Compositional data and their analysis: an introduction, in: Compositional Data Analysis in the Geosciences: From Theory to Practice. Geological Society, London, Special Publications. volume 264, pp. $1-10$.

Pawlowsky-Glahn, V., Egozcue, J., 2020. Compositional Data in Geostatistics: A Log-Ratio Based Framework to Analyze Regionalized Compositions. Math Geosci doi:https://doi.org/10.1007/s11004-020-09873-2.

Peierls, B., N. Caraco, M.P., Cole., J.J., 1991. Human influence on river nitrogen. Nature 350, 386-387.

Ramkumar, M., Muthuvairavasamy, K., Kumaraswamy, K., Mohanraj, R., 2015. Environmental Management of River Basin Ecosystems. Springer Earth System Sciences, pp.761.

Regional Functional Centre - Lazio Region, $2020 . \quad$ URL: http://www.idrografico.regione.lazio.it/. 
Rinaldo, A., Rodriguez-Iturbe, I., Rigon, R., Ijjasz-Vasquez, E., Bras, R.L., 1993. Self-organized fractal river networks. Phys. Rev. Lett. 70, 822-825. doi:10.1103/PhysRevLett.70.822.

Rodionov, S., 2004. A sequential algorithm for testing climate regime shifts. Geophys. Res. Lett. 31. doi:10.1029/2004GL019448.

Scheffer, M., Carpenter, S., Lenton, T., Bascompte, J., Brock, W., Dakos, V., van de Koppel, J., van de Leemput, I., Levin, S., van Nes, E., Pascual, M., Vandermeer, J., 2012. Anticipating critical transitions. Science 338, 344-348.

Tarboton, D.G., Bras, R.L., Rodriguez-Iturbe, I., 1988. The fractal nature of river networks. Water Resources Research 24, 1317-1322. doi:10.1029/WR024i008p01317.

Templ, M., Hron, K., Filzmoser, P., 2011. robCompositions: an R-package for robust statistical analysis of compositional data. John Wiley \& Sons Ltd.

Wald, A., Wolfowitz, J., 1940. On a test whether two samples are from the same population. The Annals of Mathematical Statistics 11. doi:http://projecteuclid.org/euclid.aoms/1177731909.

Wildlife Conservation Society and Center for International Earth Science Information Network - Columbia University, 2005. Last of the Wild Project, Version 2, 2005 (LWP-2): Global Human Influence Index (HII) Dataset (Geographic) URL: https://doi.org/10.7927/H4BPOOQC.

WWF, 2019. Climate change and water, why valuing rivers is critical to adaptation. Technical Report. WWF. 


\section{List of Figures}

1 Map of the TRB showing the drainage network and the sampling locations along the TR, which also represents the outlets of the calculated watersheds. Each colored surface represents the new contributing area which adds up to the ones upstream for the watershed delineation of the selected outlet. . . . . . . 37

2 Mean daily discharge in $\mathrm{m}^{3} / \mathrm{s}$ measured during 2017 (a) and 2018 (b) at the Ripetta flow gauge on the Tiber river. River discharge during spring and summer sampling days are highlighted in the hydrograph in blue and red color, respectively. . 38

3 Streamgraph of the lithotypes and land use characterizing the different drainage areas along the Tiber river course. Lithotypes from top to bottom (not in stratigraphic sequence): sand-silicatic sequences, karstic carbonate rock, carbonate rocks, marls and clays, riverine deposits, volcanic rocks. Land use from top to bottom: water bodies, shrub-herbaceus vegetation association, permanent crops, open spaces with little or no vegetation, heterogeneous agricultural areas, forests, artificial areas, arable lands. . . . . . . . . . . . . . 39

4 a) Scheme of the main catchment properties influencing the response to forcing agents; b) Flowchart summarizing the GRS delineation process. . . . . . . . . . . . . . . . . 40 
5 Robust compositional biplot for clr-transformed major species data jointly with PCs loading plots. Scores are represented with different symbols and colors according to the sampling location (High-Middle Tiber (HMT) or Low Tiber(LT)) and season (flood or drought conditions), respectively. . . . . . . . 41

6 Robust compositional biplot for clr-transformed minor and trace species data jointly with PCs loading plots. Scores are represented in different symbols and colors according to the sampling location (High-Middle Tiber (HMT) or Low Tiber(LT)) and season (flood or drought conditions), respectively. . . . . . 42

7 Robust biplot for drivers data jointly with PCs loading plots. Scores are represented in different symbols and colors according to the sampling location (High-Middle Tiber (HMT) or Low Tiber(LT)) and season (flood or drought conditions), respectively. The considered drivers are the following: arable lands (AL), Human Impact Index (HII), carbonate rocks (Carb.), sand-silicatic successions (Sand-Silic.), forests, slope and elevation (Elev.). . . . . . . . . . . . . . . . 43

8 Chemical Index 1 and Forcing index 1 for flood (a) and drought (c) hydrological conditions plotted versus the distance from the TR source and (b) bar plots showing deviations from their respective medians (b and c). Vertical lines in (a) and (c) indicate the spacing of a potential GRS, while the colored areas in (b) and (d) highlight the distance for which the new state is preserved. . . . . . . . . . . . . . . 44 
9 Chemical Index 1 and Forcing index 2 for flood (a) and drought (c) hydrological conditions plotted versus the distance from the TR source and (b) bar plots showing deviations from their respective medians (b and c). Vertical lines in (a) and (c) indicate the spacing of a potential GRS. . . . . . . . . . . . 45

10 Trace Chemical Index 1 and Forcing index 1 for flood (a) and drought (c) hydrological conditions plotted versus the distance from the TR source and bar plots showing deviations from their respective medians ( $b$ and $c$ ). Vertical lines in (a) and (c) indicate the spacing of a potential GRS. . . . . . . . . . 46 


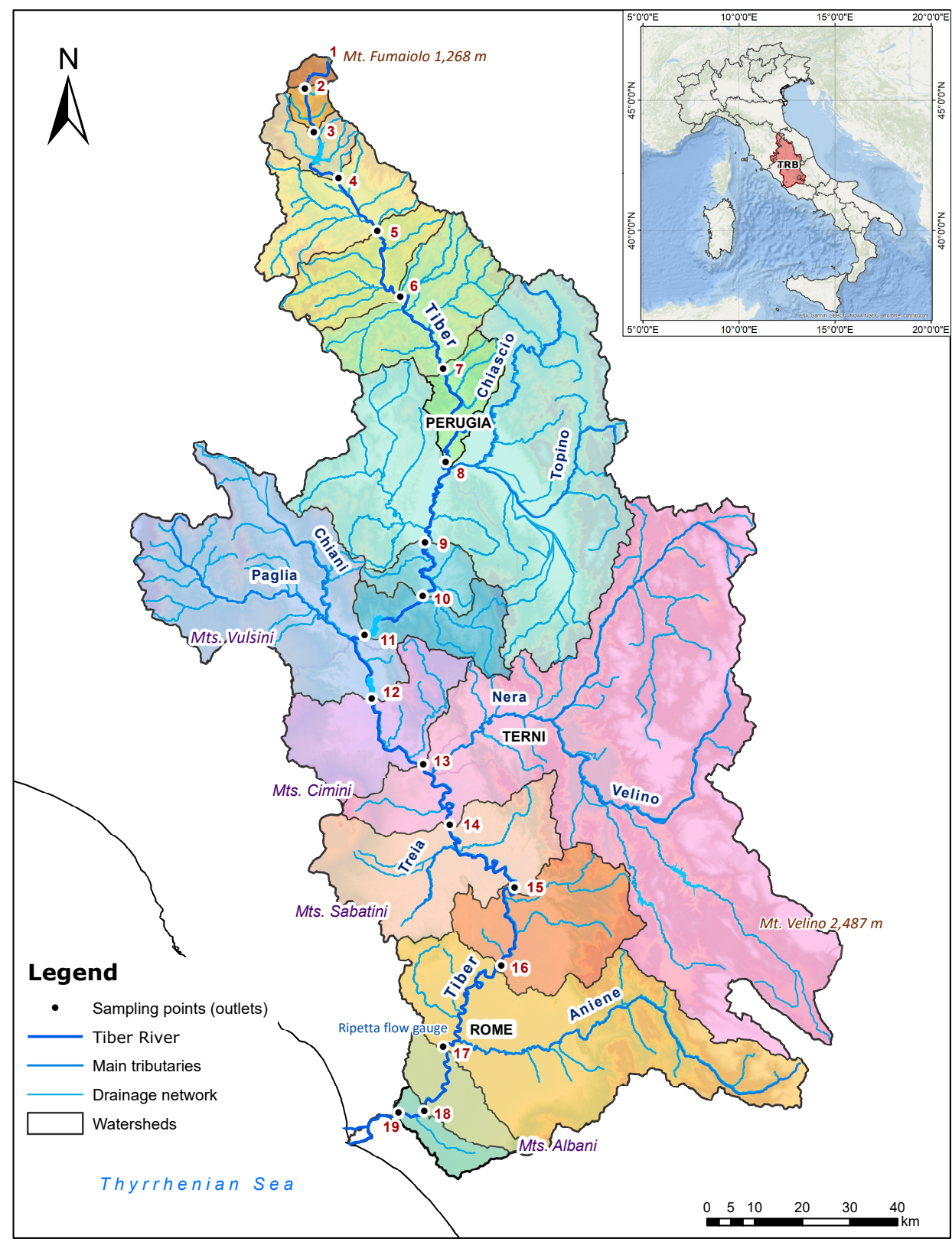

Figure 1: Map of the TRB showing the drainage network and the sampling locations along the TR, which also represents the outlets of the calculated watersheds. Each colored surface represents the new contributing area which adds up to the ones upstream for the watershed delineation of the selected outlet. 

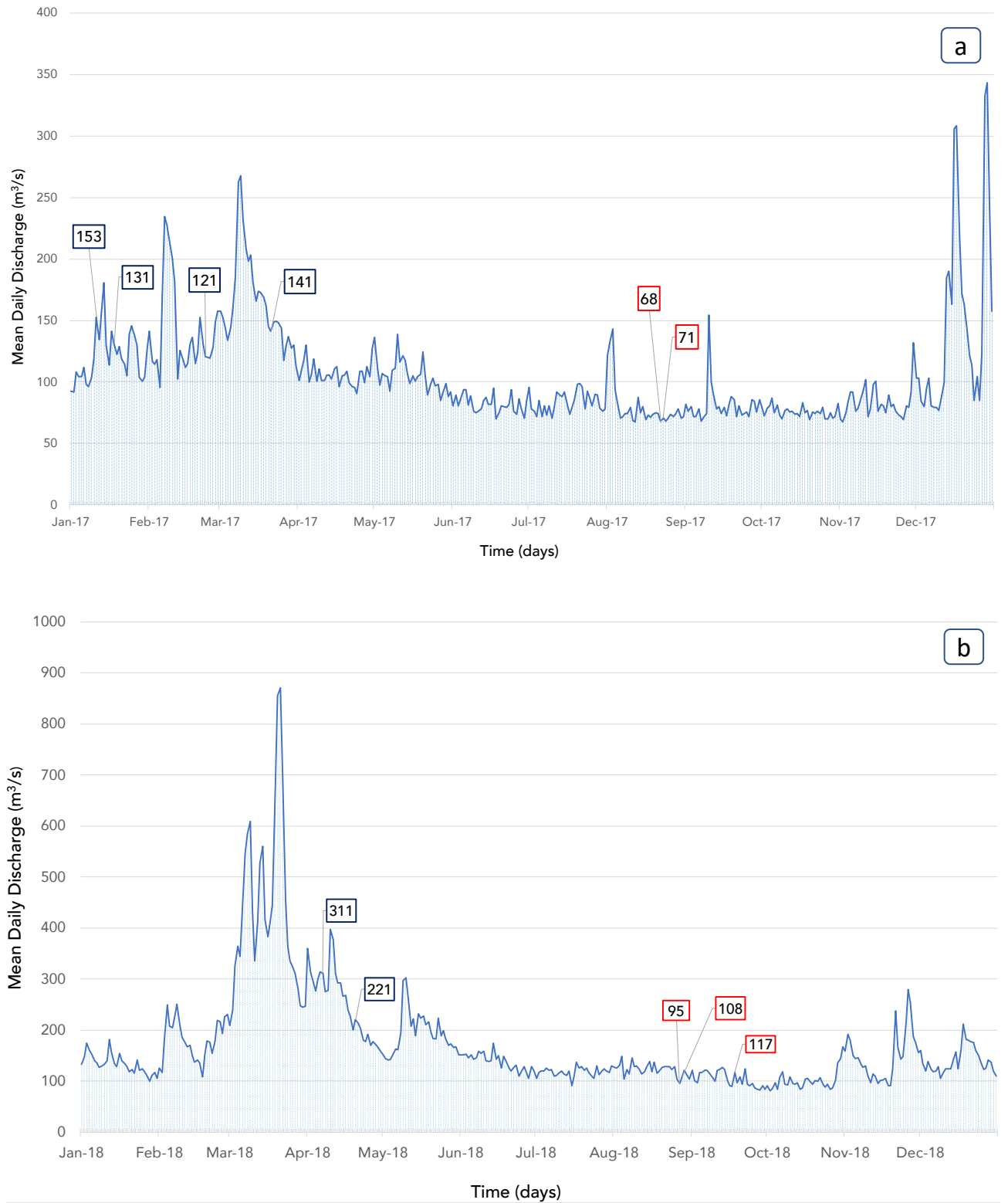

Figure 2: Mean daily discharge in $\mathrm{m}^{3} / \mathrm{s}$ measured during 2017 (a) and 2018 (b) at the Ripetta flow gauge on the Tiber river. River discharge during spring and summer sampling days are highlighted in the hydrograph in blue and red color, respectively. 

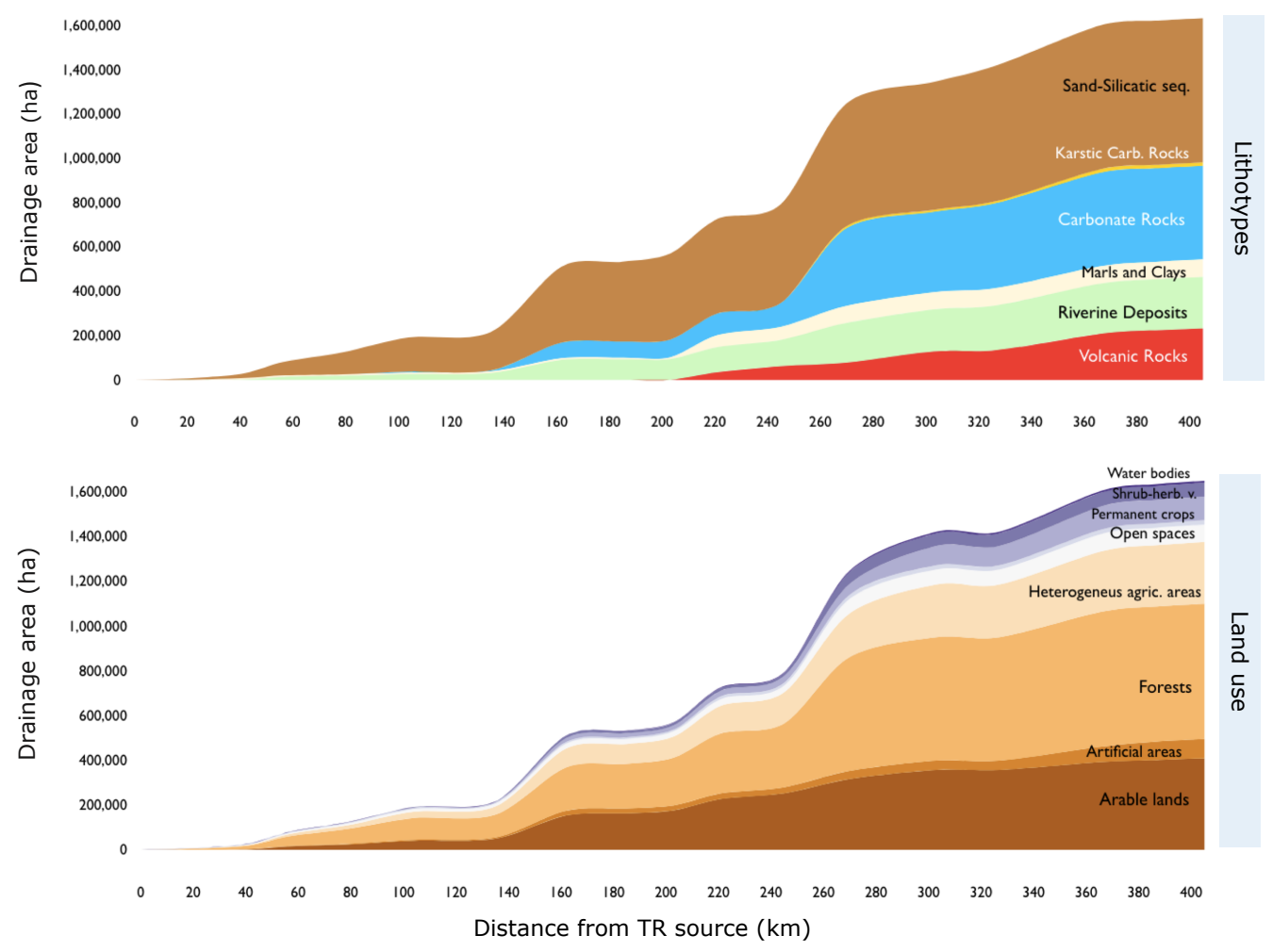

Figure 3: Streamgraph of the lithotypes and land use characterizing the different drainage areas along the Tiber river course. Lithotypes from top to bottom (not in stratigraphic sequence): sand-silicatic sequences, karstic carbonate rock, carbonate rocks, marls and clays, riverine deposits, volcanic rocks. Land use from top to bottom: water bodies, shrub-herbaceus vegetation association, permanent crops, open spaces with little or no vegetation, heterogeneous agricultural areas, forests, artificial areas, arable lands. 


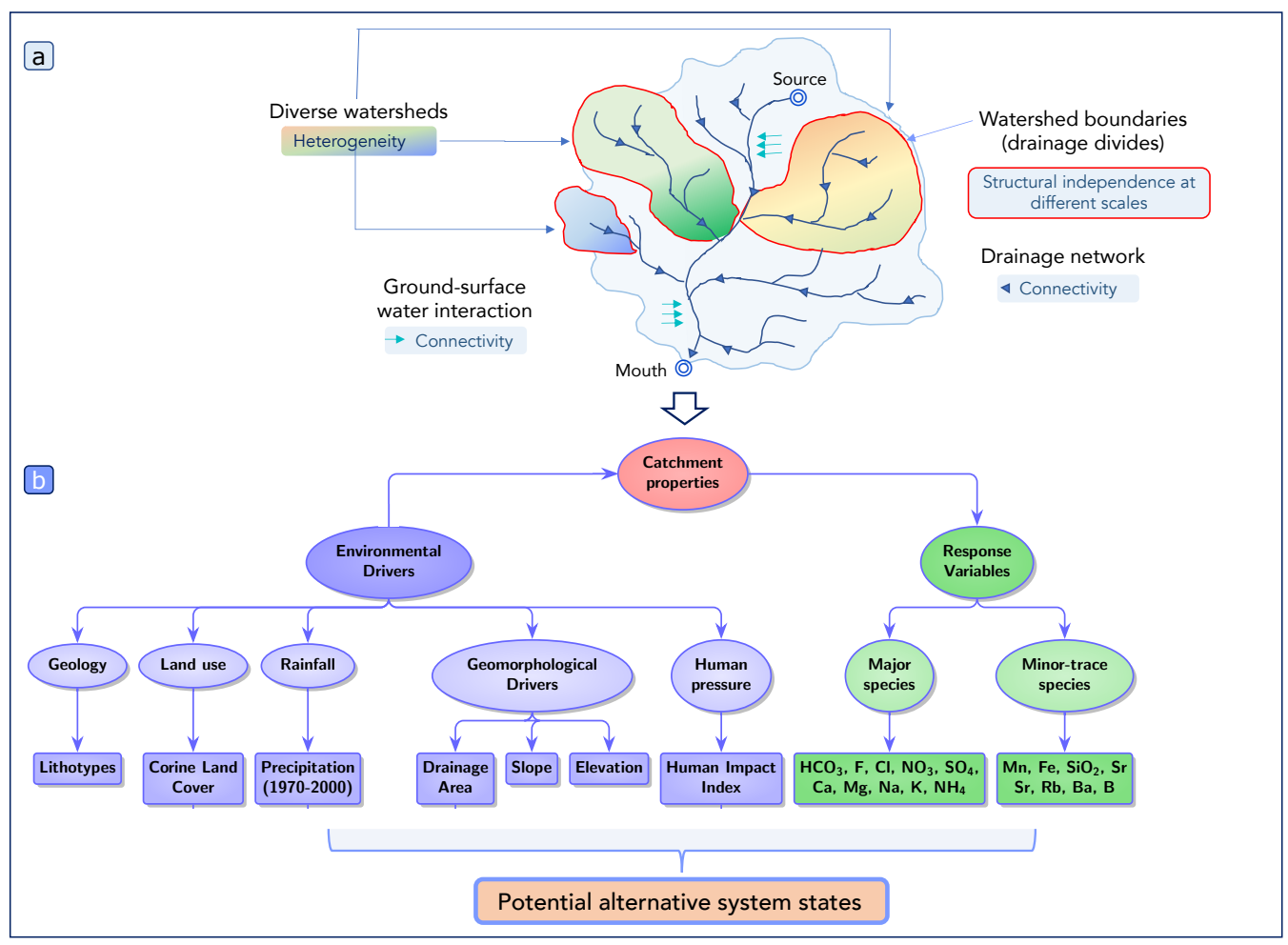

Figure 4: a) Scheme of the main catchment properties influencing the response to forcing agents; b) Flowchart summarizing the GRS delineation process. 

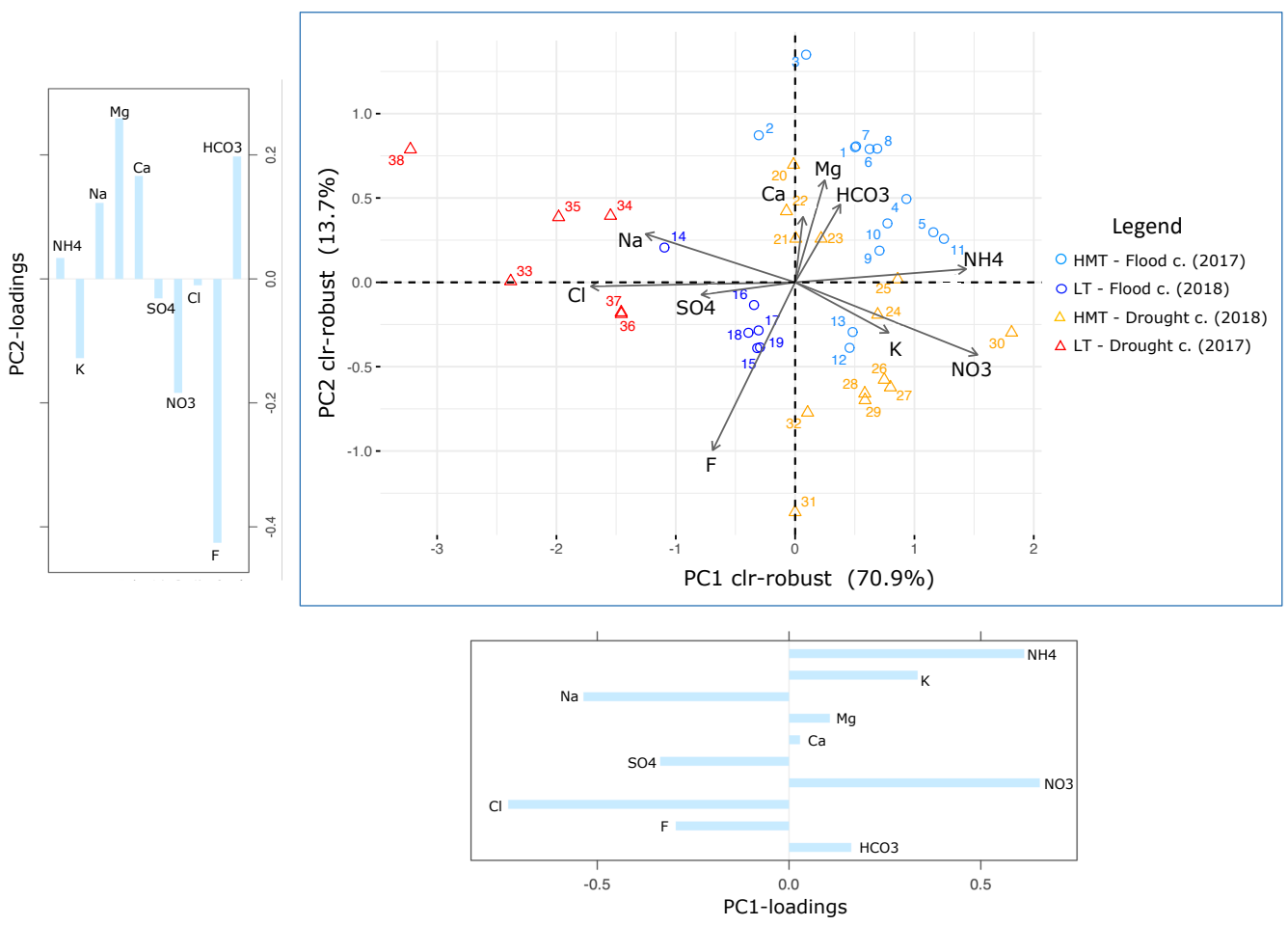

Figure 5: Robust compositional biplot for clr-transformed major species data jointly with PCs loading plots. Scores are represented with different symbols and colors according to the sampling location (High-Middle Tiber (HMT) or Low Tiber(LT)) and season (flood or drought conditions), respectively. 


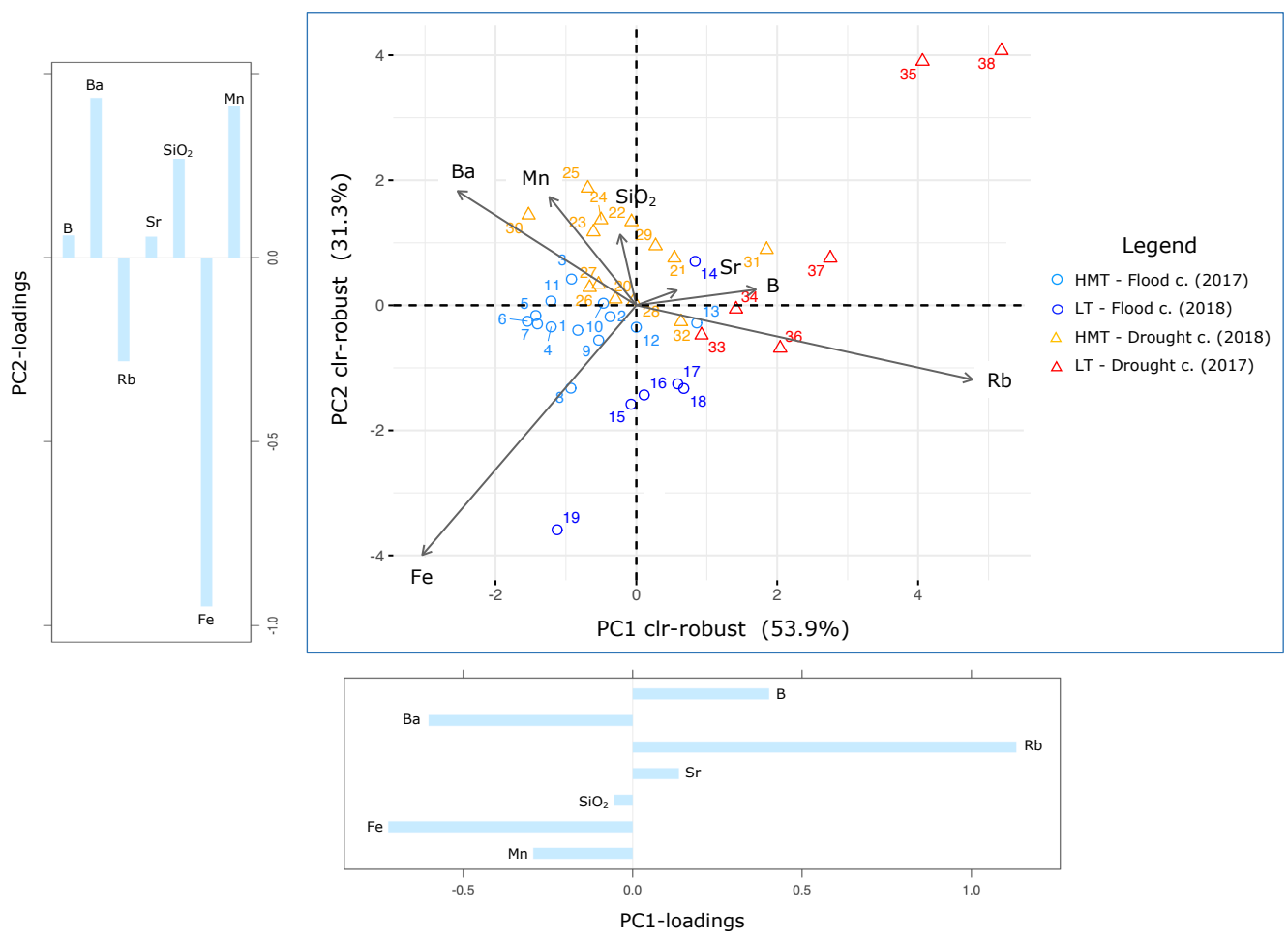

Figure 6: Robust compositional biplot for clr-transformed minor and trace species data jointly with PCs loading plots. Scores are represented in different symbols and colors according to the sampling location (High-Middle Tiber (HMT) or Low Tiber(LT)) and season (flood or drought conditions), respectively. 


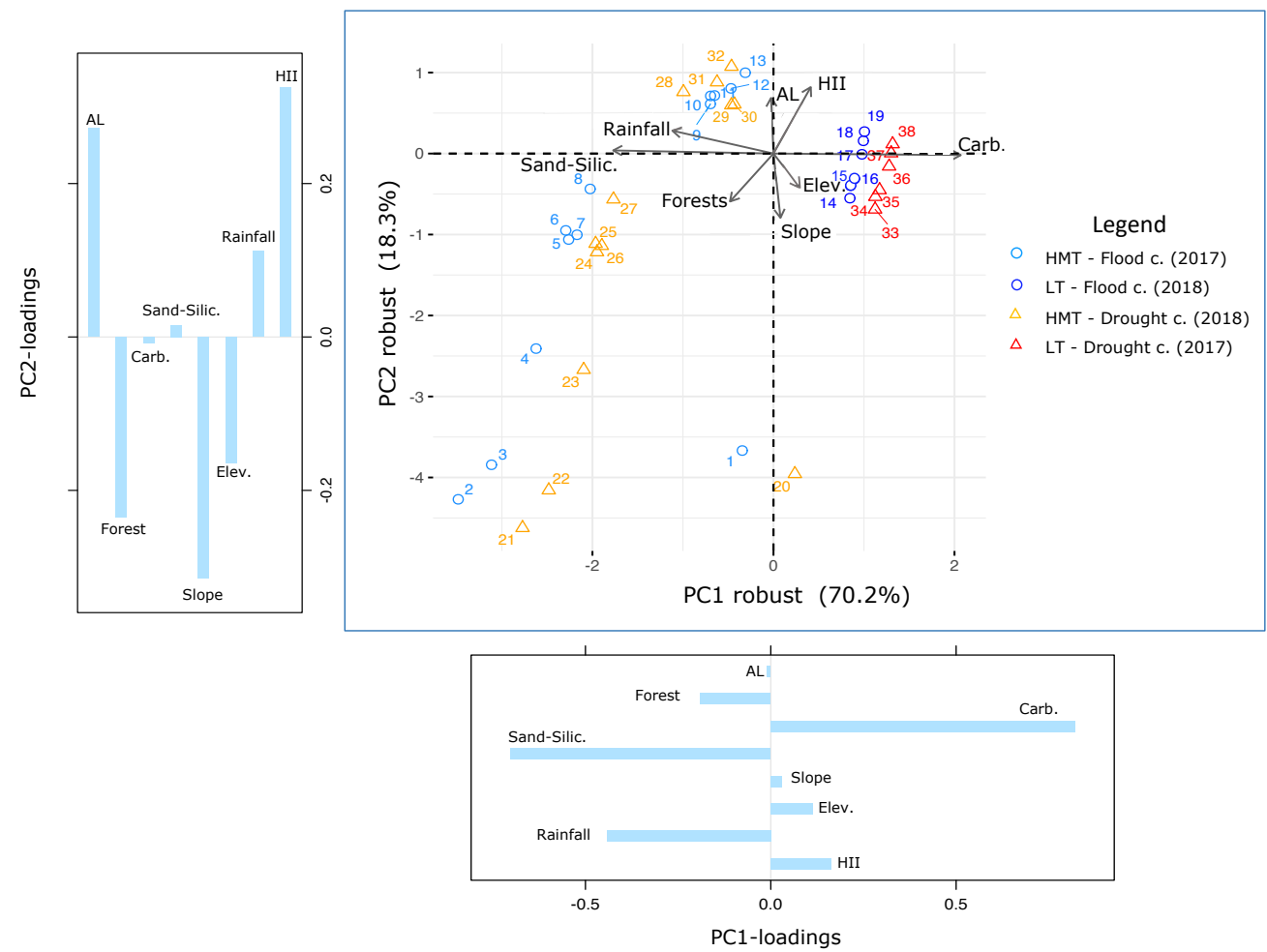

Figure 7: Robust biplot for drivers data jointly with PCs loading plots. Scores are represented in different symbols and colors according to the sampling location (High-Middle Tiber (HMT) or Low Tiber(LT)) and season (flood or drought conditions), respectively. The considered drivers are the following: arable lands (AL), Human Impact Index (HII), carbonate rocks (Carb.), sand-silicatic successions (Sand-Silic.), forests, slope and elevation (Elev.). 

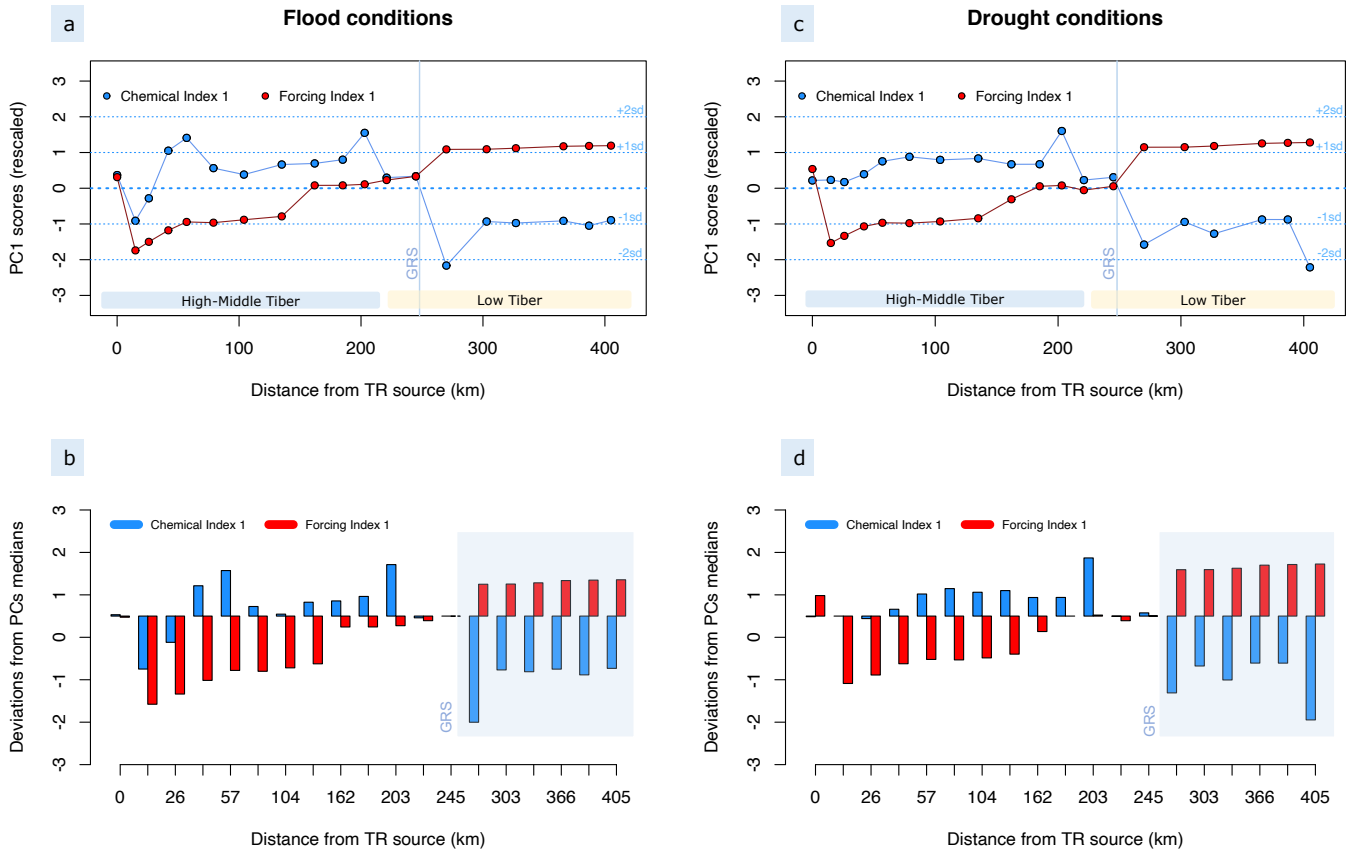

Figure 8: Chemical Index 1 and Forcing index 1 for flood (a) and drought (c) hydrological conditions plotted versus the distance from the TR source and (b) bar plots showing deviations from their respective medians (b and c). Vertical lines in (a) and (c) indicate the spacing of a potential GRS, while the colored areas in (b) and (d) highlight the distance for which the new state is preserved. 

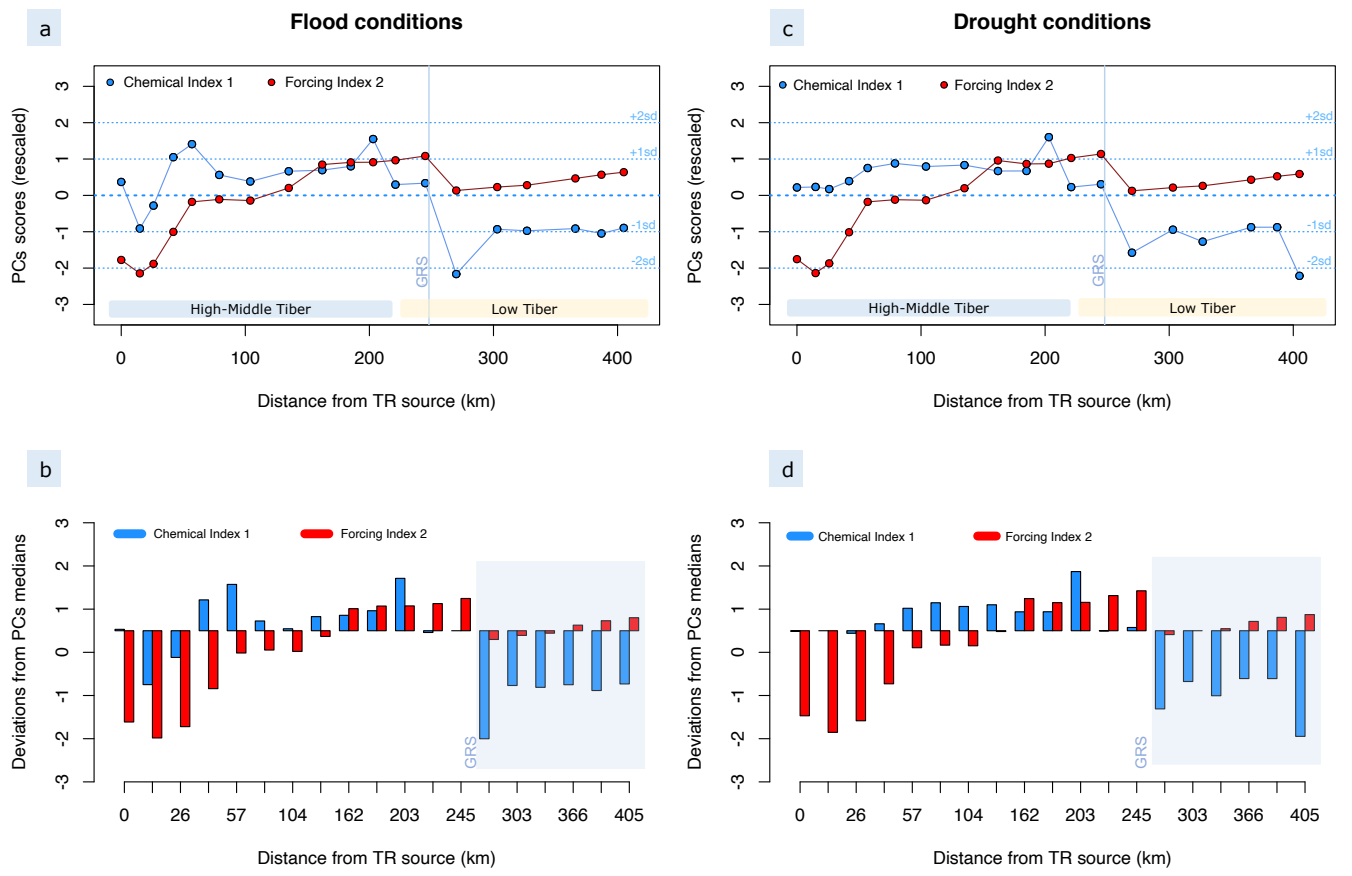

Figure 9: Chemical Index 1 and Forcing index 2 for flood (a) and drought (c) hydrological conditions plotted versus the distance from the TR source and (b) bar plots showing deviations from their respective medians (b and c). Vertical lines in (a) and (c) indicate the spacing of a potential GRS. 

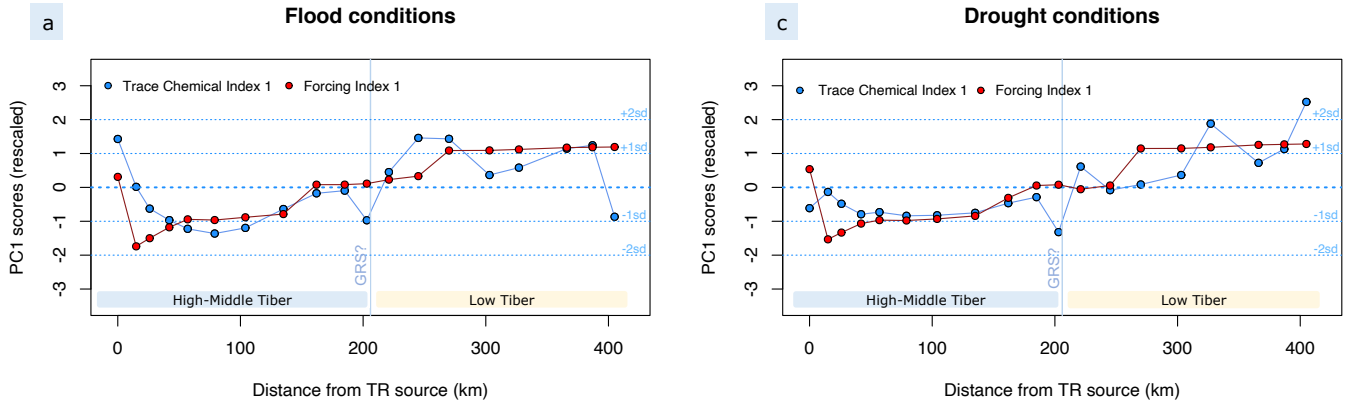

b

d
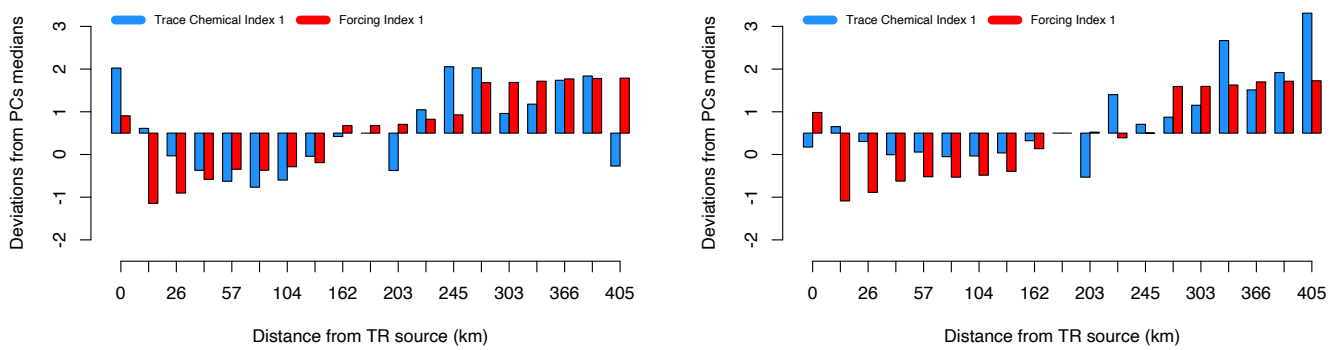

Figure 10: Trace Chemical Index 1 and Forcing index 1 for flood (a) and drought (c) hydrological conditions plotted versus the distance from the TR source and bar plots showing deviations from their respective medians (b and c). Vertical lines in (a) and (c) indicate the spacing of a potential GRS. 